\title{
An active indirect solar system for food products drying
}

\author{
Abdul Wasim Nooria, ${ }^{\mathrm{a}}$, Mohammad Jafar Royen ${ }^{\mathrm{a}, \mathrm{b}}$, Juma Haydary \\ ${ }^{a}$ Institute of Chemical and Environmental Engineering, Slovak University of Technology in Bratislava, \\ Radlinského 9, 81237 Bratislava, Slovakia, juma.haydary@stuba.sk \\ ${ }^{b}$ Faculty of Chemical Technology, Kabul Polytechnic University, Kart-e Mamoorin, Kabul, Afghanistan, \\ awnoori@kpu.edu.af
}

\begin{abstract}
An energy independent active indirect solar drying system for the study of food products drying at specific climate conditions was developed and tested. As a model material, sliced tomato was selected because of its short shelf live, high humidity and potential to be a high value dried product. Indirect solar dryer enabled complete protection of the dried material against sunlight, birds, insects, rain and dust during the drying process. The solar dryer system design includes a rectangular section $(1000 \times 600 \times 400) \mathrm{mm}$ chamber and a flat solar collector $(1500 \times 600 \times 100) \mathrm{mm}$ with the surface area of $0.9 \mathrm{~m}^{2}$. Air flow was induced by a fan installed at the inlet of the collector and powered by a photovoltaic solar panel and a battery system. Temperature and humidity of air were monitored at the collector inlet, collector outlet and the drying chamber outlet. The key element of the collector is a $10.5 \mathrm{~m}$ long rectangular section aluminum pipe $(55 \times 35) \mathrm{mm}$ coated with an absorption layer. The maximum dryer capacity is around $3 \mathrm{~kg}$ of wet material (sliced tomato) per batch. Average air temperature increase in the collector was measured to be $30{ }^{\circ} \mathrm{C}$ during the winter season. Air relative humidity decreased from $21 \%$ to $15 \%$ after passing through the collector. The moisture of tomato slices decreased from the initial value of $92 \%$ down to $22 \%$ during the time of the experiment ( $30 \mathrm{~h})$. Quality of tomatoes dried using the designed solar dryer differed significantly in color as well as in texture from those dried by the commonly used methods, like an open sun drying system. Equilibrium moisture content of the product was reached after $30 \mathrm{~h}$ in December when the maximum outside temperature was $17.6^{\circ} \mathrm{C}$. The tomato mass decreased from $333 \mathrm{~g}$ to $33.15 \mathrm{~g}$; the mass loss being approximately $90 \%$. The heated air temperature and humidity at the dryer inlet and outlet were influenced by the change of the ambient temperature and humidity during the day. Variation of the drying rate with the change of the ambient temperature and humidity was observed. During summer, when the sun radiation increases, the drying time for sliced tomato with $9 \mathrm{~mm}$ thickness decreased from $25 \mathrm{~h}$ to $15 \mathrm{~h}$. The sample thickness also has an impact on the drying process. When the sample thickness increased from $9 \mathrm{~mm}$ to $12 \mathrm{~mm}$, the drying time increased from $15 \mathrm{~h}$ to $20 \mathrm{~h}$ of active device time.
\end{abstract}

Key words: Active indirect solar dryer, renewable energy, drying, upland condition, sliced tomatoes

\section{Introduction}

Most food products require some kind of preservation to enhance their shelf life since the production usually exceeds the market demand during the harvest season. For example: application of heat or cold, chemical substances, fermentation, mechanical methods and combinations of two or more of the mentioned methods (Mathavi et al., 2013), as well as modern methods like ultraviolet light processing and pulsed light processing (Rahman, 2007; Abida et al., 2014), microwave preservation (Barrett and Lloyd, 2012), highpressure processing (Kadam et al., 2012), ionizing radiation, ultraviolet radiation (Abida et al., 2014), biopreservation (Acuña et al., 2011), etc., are used. Drying is the most used and most suitable method for agricultural products preservation (Srisittipokakun et al., 2012).

The most popular and current techniques for agricultural products dehydration include open sun drying (Akpinar, 2010), solar drying (direct and indirect) (Mohamed et al., 2008), convective drying (Royen et al., 2018), drum drying (Mujumdar, 2014), spray drying (Sormoli and Langrish, 2016), fluidized-bed drying (Senadeera et al., 2013), freeze drying (Kudra and Mujumdar, 2009), microwave drying (Pu et al., 2016), osmotic drying (Karam et al., 2016), vacuum drying (Sagar and Kumar, 2010), ultrasound drying (Mulet et al., 2003), etc. However, drying is generally an energy-intensive operation and it can significantly affect the cost of the product. High prices and shortages of fossil fuels increase the emphasis on the use of solar energy as an alternative energy source, especially in developing countries (Tiris et al., 1996). Indirect solar drying represents a cost effective method for food products drying in many countries including Afghanistan where this research was done.

Afghanistan is a landlocked country located in the center of Asia. Economy of the country is based on agribusiness (Finck-Pastrana, 2014; World bank, 2014) as agriculture creates approximately $1 / 3$ of 
the gross domestic product, GDP, and employs an estimated $80 \%$ of the Afghan population directly or indirectly (Ward and Jalal, 2011). Afghanistan's climate is perfectly suitable for high-valued fruits, vegetables and herbal plants' cultivation (Shukla et al., 2017). Environmental conditions of the country are highly favorable for many tree crops, vegetable species and herbal plant production (Kemal-urRahim, 2003; Bhardwaj, 2012). Dry products which are famous all over the world also include almonds, walnuts and pistachios, apricots, cherries, plums and raisins (Rasoly and Chandrashekar, 2018; Ministry of Industry and Commerce, Islamic Republic of Afghanistan, 2018). The world popular herbal plants which are grown and cultivated here are saffron, onions, peppermint, garlic, chamomile, chicory, flixweed, liquorice, fumitory, sage, marshmallow, dill, fennel, harmal or syrian rue (Amini and Hamdam, 2017). The major export agriculture product is dried fruits $(27 \%)$, medicinal plants $(10 \%)$ and fresh fruits $(7 \%)$ (Salman, 2017). However, one of the major limitations in dried product business in Afghanistan is to meet the standards and requirements for hygiene of the drying process. Open sun drying, which is the most often used method, does not meet these requirements. On the other hand, conventional hot air drying is very energy intensive. Solar drying under controlled conditions can be an alternative to the hot air and open sun drying methods, especially in locations with good sunshine during the harvest season (Sunil et al., 2012). A wide variety of solar dryers have been designed by many researchers (Mehta et al., 2018; Sengar et al., 2009; Rathore and Panwar, 2010; Sharma et al., 2009). Solar dryers are classified into two types, active and passive ones, each working in three modes: direct, indirect and mixed (Sharma et al., 2009; Srisittipokakun et al., 2012; Boughali et al., 2009; Wang et al., 2018; Zoukit et al., 2019; ShamekhiAmiri et al., 2018; El Khadraoui et al., 2017). Solar drying systems, especially indirect active ones need shorter time for the drying process completion than the open sun light systems (Sunil et al., 2012), lower energy consumption than conventional hot air drying systems and they enable control of the hygienic conditions of the process.

Indirect active solar cabinet dryers are considered more advanced compared to typical cabinet dryers because they generally consist of two separate components: a collector that heats air with solar radiation and a drying chamber in which scales or planks of the product are accommodated. The operating principle is similar to that of a cabinet dryer; however, ambient air is driven to the collector by a ventilator (fan or blower). Active indirect solar dryer is more suitable for agricultural products with high moisture content, such as fruits, vegetables and herbal plants (El Khadraoui et al., 2017; Mujumdar, 2014).

Advantages of indirect forced solar dryer are that the samples are not exposed to solar radiation, the product quality does not decrease significantly and unstable vitamins and nutrients content is not reduced as much, drying rate is higher than in unforced systems and it is controllable (Phadke et al., 2015). Disadvantages of this system include higher initial costs and higher operation expenses due to intense circulation of heated air by fan or another kind of blower (Sontakke and Salve, 2015).

Afghanistan is one of the countries with a huge potential for using solar energy as it has more than 300 sunny days per year and high potential of solar energy production with the average capacity of $4-6.5 \mathrm{kWh} / \mathrm{m}^{2} /$ day (Jahangiri et al., 2019). Nowadays, solar energy is used for cooking, lighting, water heating and food drying in Afghanistan (Shukla et al., 2017). However, traditional open sun drying methods without quality control and standard hygiene conditions fulfilment are still applied (Abur et al., 2014).

The principal objective of this work was to design and test an energy independent solar drying system for food products drying in the indirect mode to achieve complete protection of fruit and vegetable against sunlight, birds, insects, rain and dust during the drying process producing standard dried products for worldwide market (Sontakke and Salve, 2015; Aiswarya and Divya, 2015). As a model material, sliced tomato was selected because of its short shelf live, high humidity and its potential to be a high added-value dried product. Tomato (Lycopersicum esculentum) is an herbaceous plant which is part of the family Solanaceous like potato (Manaa et al., 2013).

\section{Materials and Methods}

\section{Solar Dryer}

A scheme of the designed solar dryer system is shown in Fig. 1. The system includes a rectangular $(1000 \times 600 \times 400) \mathrm{mm}$ chamber and a flat solar collector $(1500 \times 600 \times 100) \mathrm{mm}$ with the surface area of $0.9 \mathrm{~m}^{2}$. Air flow was induced by a fan installed at the inlet of the collector and powered by a photovoltaic solar panel and a battery system. Temperature and humidity of air were monitored at the collector inlet, collector outlet and the drying chamber outlet. The key element of the collector is a $10.5 \mathrm{~m}$ long rectangular section aluminum pipe $(55 \times 35) \mathrm{mm}$ coated with an absorption layer. The dryer capacity is around $3 \mathrm{~kg}$ of wet material (sliced tomato) per batch. 


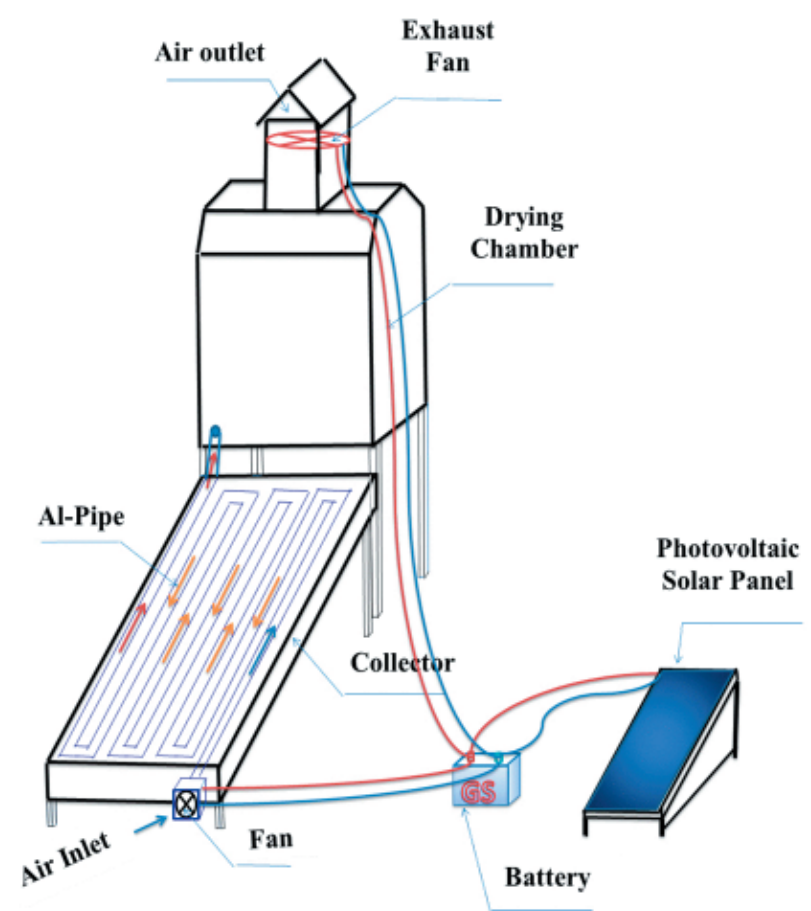

Fig. 1. Characteristics of solar dryer collector and chamber.

\section{Samples}

Fresh and ripe tomatoes with approximately equal size and color were selected and purchased from a Kabul local market. Then, they were washed with tap water before sliced to pieces with circular shape with $9 \mathrm{~mm}$ and $12 \mathrm{~mm}$ thickness using a stainless steel knife. The average diameter of tomatoes was around $5 \mathrm{~cm}$. For each batch, around $323 \mathrm{~g}$ of sliced tomatoes were distributed in a single layer in the dryer chamber. The samples were weighted by a digital balance with the capacity ranging from $0.01 \mathrm{~g}$ up to $500 \mathrm{~g}$ with $\pm 0.01 \mathrm{~g}$ precision.

\section{Experimental procedure}

Chamber and trays were washed and cleaned before the samples were distributed. Initial moisture content of tomato slices measured by a laboratory moisture analyzer equipped with an analytical moisture balance (capacity 0.001-160 g, VWR, Italy) was 0.95 (wet base). Duration of the experiments and active drying time during the day depended on the season. In summer, experiments started at 8:00 AM and were finished at 5:00 PM, $9 \mathrm{~h}$; while in winter, the experiments started at 9:30 AM and continued until 2:30 PM for 5 consecutive hours. After every $60 \mathrm{~min}$, the sample mass loss was recorded. During the active drying periods, the temperature and relative humidity of air stream at the solar collector inlet, solar collector outlet and at the chamber outlet were monitored. During winter, the maximum ambient temperature was around $18{ }^{\circ} \mathrm{C}$ and in the summer it was $38^{\circ} \mathrm{C}$. The range of ambient air relative humidity was (13-21\%), and the air pressure was around $80-82 \mathrm{kPa}$. The data were recorded by an automatic data logger. The last step of the drying process was the device discharging. The average air velocity measured at the outlet of the solar collector (circular part of the pipe with a diameter of $50.8 \mathrm{~mm}$ ) was $0.6 \mathrm{~m} / \mathrm{s}$.

\section{Results and discussion}

The collector efficiency was tested by measuring the air temperature before and after the collector during the winter season (December), under extreme conditions (minimum sunshine time and lowest ambient temperatures in Kabul). Temperature behavior during the measurement days are presented in Fig. 2. The collector inlet temperature during the active measurement period was between $10^{\circ} \mathrm{C}$ and $18{ }^{\circ} \mathrm{C}$. The maximum increase of air temperature after passing the collector was from $17^{\circ} \mathrm{C}$ up to $47^{\circ} \mathrm{C}$. Also, the effect of temperature changes during the day can be seen in this figure. The maximum air outlet and inlet temperature difference (maximum collector efficiency) corresponds to conditions at noon, when the sun radiation angle is more perpendicular to the collector surface. These measurements showed that the system can be used during the whole year including the winter season when the temperature is low and sunshine time is short.

Fig. 3 shows the sample mass loss versus time in winter season. Active drying time (time with hot air flow inside the chamber) was $5 \mathrm{~h}$ per day. Total time needed for complete drying was five days. In experiments done in summer (June), the total drying time was reduced to two days (Fig. 4). Total mass loss of the sample was around $90 \%$ in winter and $92 \%$ in summer. Equilibrium moisture content of the product was reached after $25 \mathrm{~h}$ of active drying during winter season and after $15 \mathrm{~h}$ of active drying during summer season.

Of course, the dryer works more effectively during the summer season when ambient temperature is higher (30-40 ${ }^{\circ} \mathrm{C}$ in Kabul). Fig. 4 presents the mass loss variation with time for two samples with different slice thickness obtained in summer when ambient lowest and highest air temperatures were $18^{\circ} \mathrm{C}$ and $36{ }^{\circ} \mathrm{C}$, respectively. When the slice thickness increased from $9 \mathrm{~mm}$ to $12 \mathrm{~mm}$, the time required to achieve equilibrium moisture content increased from $15 \mathrm{~h}$ (two device working days) to $20 \mathrm{~h}$ (three device working days). As it results from Fig. 4, in the initial drying period when free water from the sample surface is evaporated, the drying rate is not 


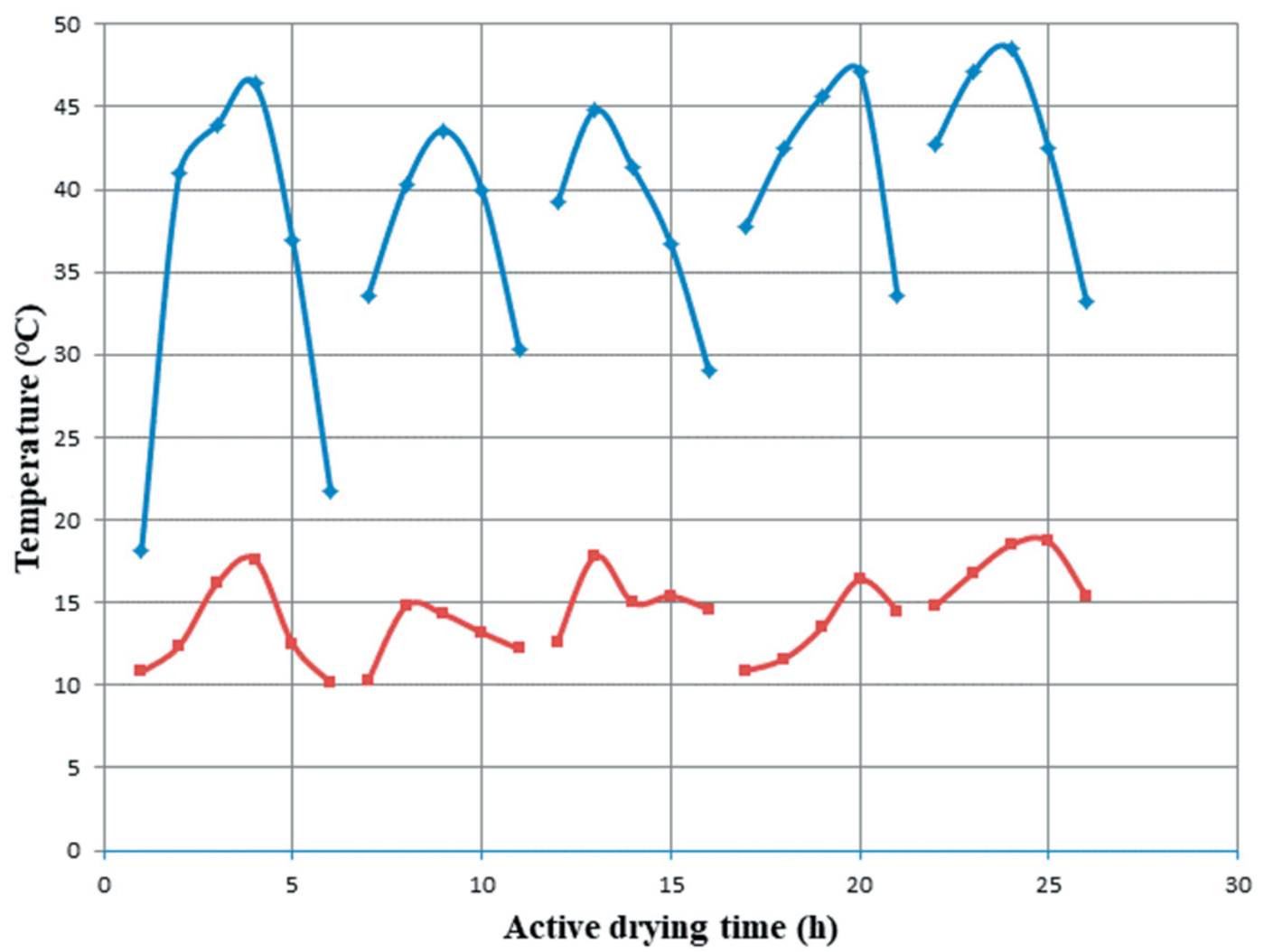

Fig. 2. Collector efficiency shown as air temperature increase after passing the collector. Gapes between the curves represent measurement discontinuance during the night.

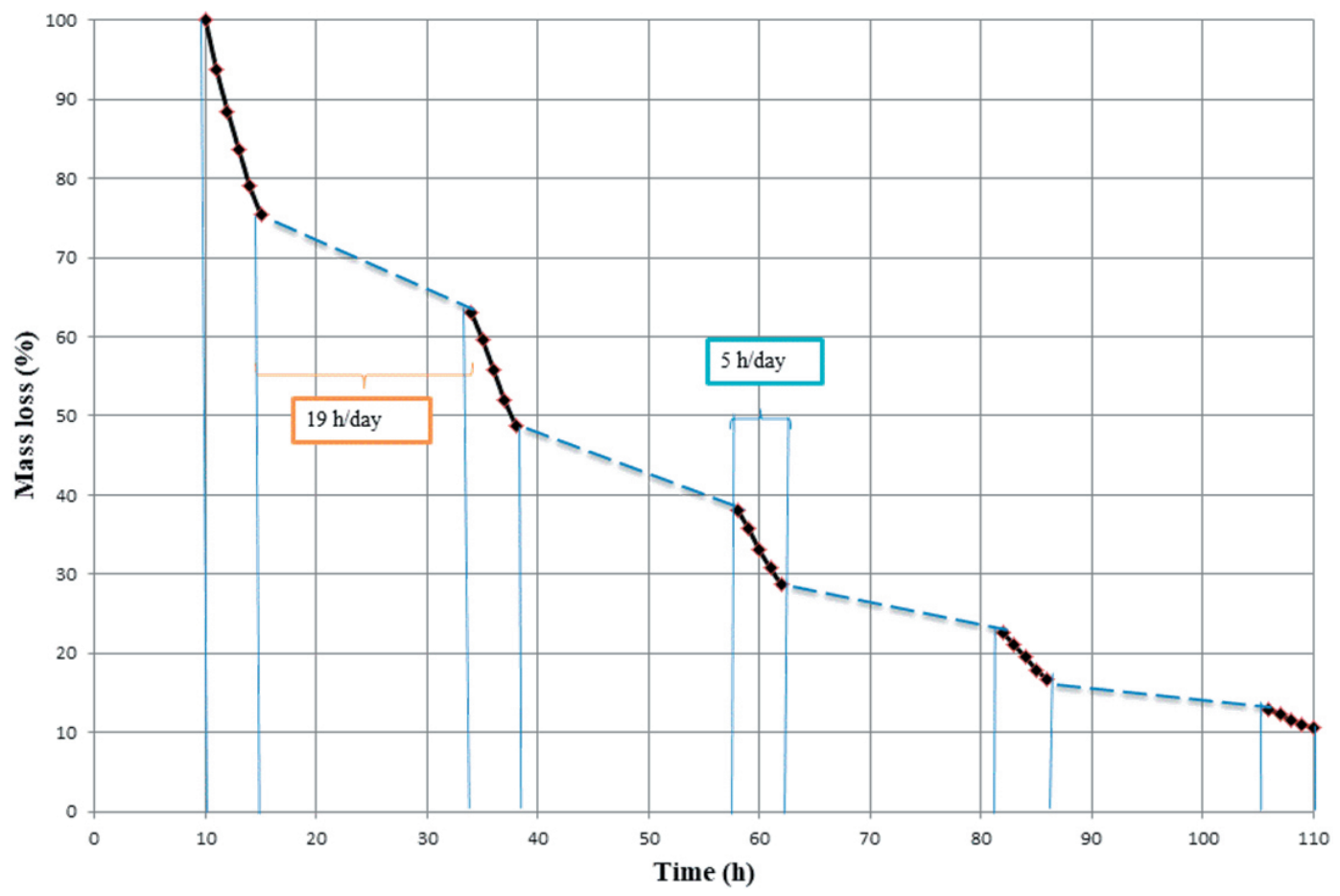

Fig. 3. Sample mass loss versus drying time.

influenced by the slice thickness. Later, when water diffusion to the surface takes place, drying rate is influenced by the sample slice thickness.

Comparing active solar drying periods (periods with forced air circulation) and periods with only natural circulation (Figs. 3 and 4), the effect of hot air circulation can be observed. Drying rate obtained during the forced air circulation periods is in average around 7.8 times higher than that observed during the natural air circulation periods. 


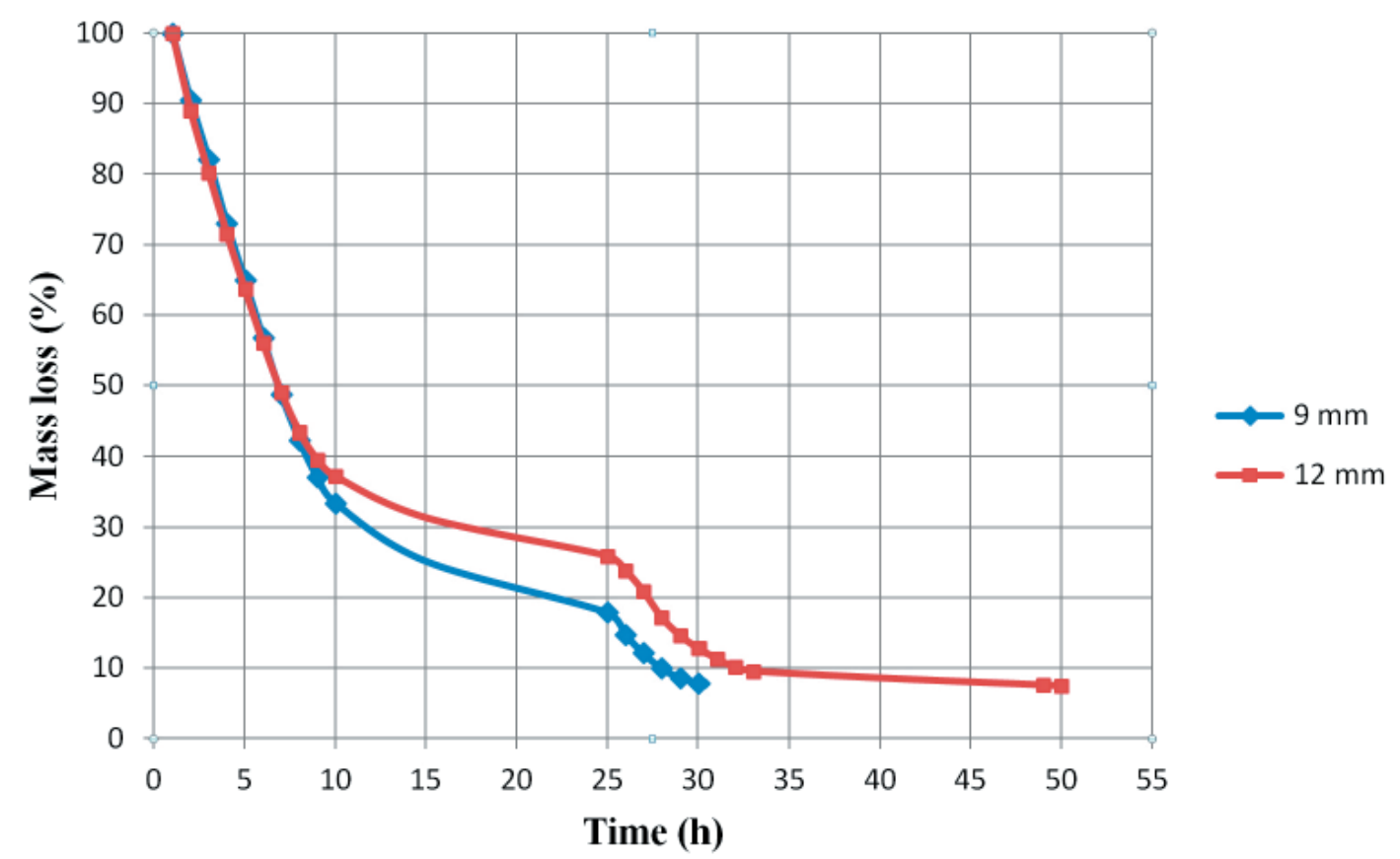

Fig. 4. Effect of tomato slice thickness on drying time.

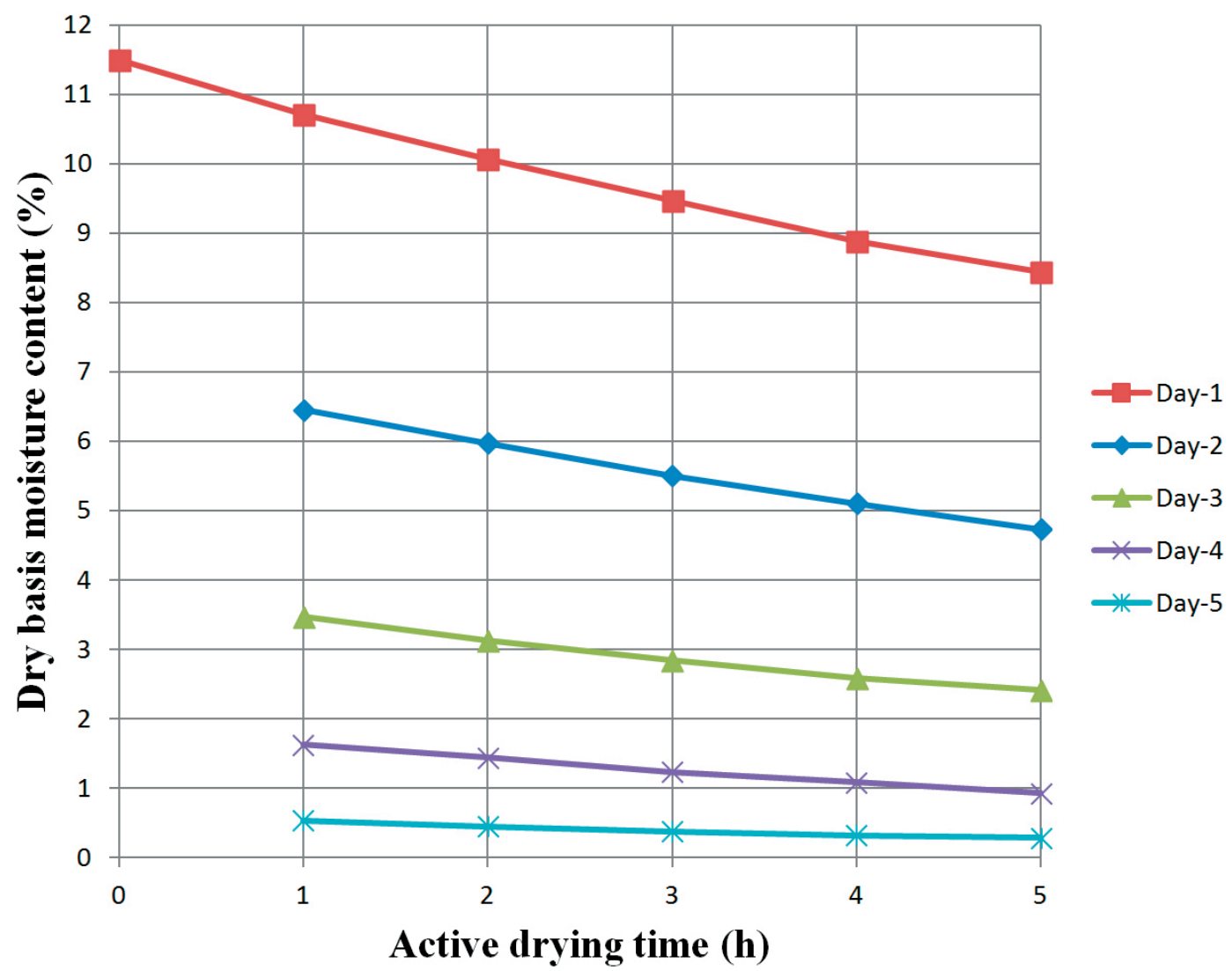

Fig. 5. Decrease of wet material moisture content with the drying time.

In winter, the device worked in active mode just for $5 \mathrm{~h}$ each day. In Fig. 3, the gaps between measurement points shown by dashed lines represent $19 \mathrm{~h}$ off-time per day. The decrease of the tomato moisture content (dry basis) for each day is shown in Fig. 5. The dry basis moisture content in tomato slices decreased from the initial value of 11.5 (92\% wet basis) down to 0.3 (22\% wet basis) during $25 \mathrm{~h}$ of active drying.

One of the most important parameters influencing the rate of drying is air relative humidity. Relative humidity of air was measured in three different points: in the stream entering the collector (relative humidity of ambient air), after the collector (at the drying chamber 
inlet) and at the chamber outlet. Fig. 6 shows the air humidity in all three points during the active mode of the device. Air humidity changed during the process and also during the day. The range of ambient air relative humidity was (13-21\%), the air relative humidity decreased to (6-17\%) after passing the collector, and it increased to $(40-75 \%)$ at the chamber outlet. As it results from Fig. 6, the change of temperature during the day influenced also the ambient air relative humidity. It is most visible for the air leaving the drying chamber. These measurements provide very important information that at geographical locations such as Afghanistan, the device can work with acceptable driving force also under extreme winter conditions and at low air velocity. At higher air velocities, smaller change in air relative humidity in the device can be expected, which means higher driving force for the mass transfer.

Drying rate is affected mainly by air relative humidity and air temperature. Eq. (1) was used to

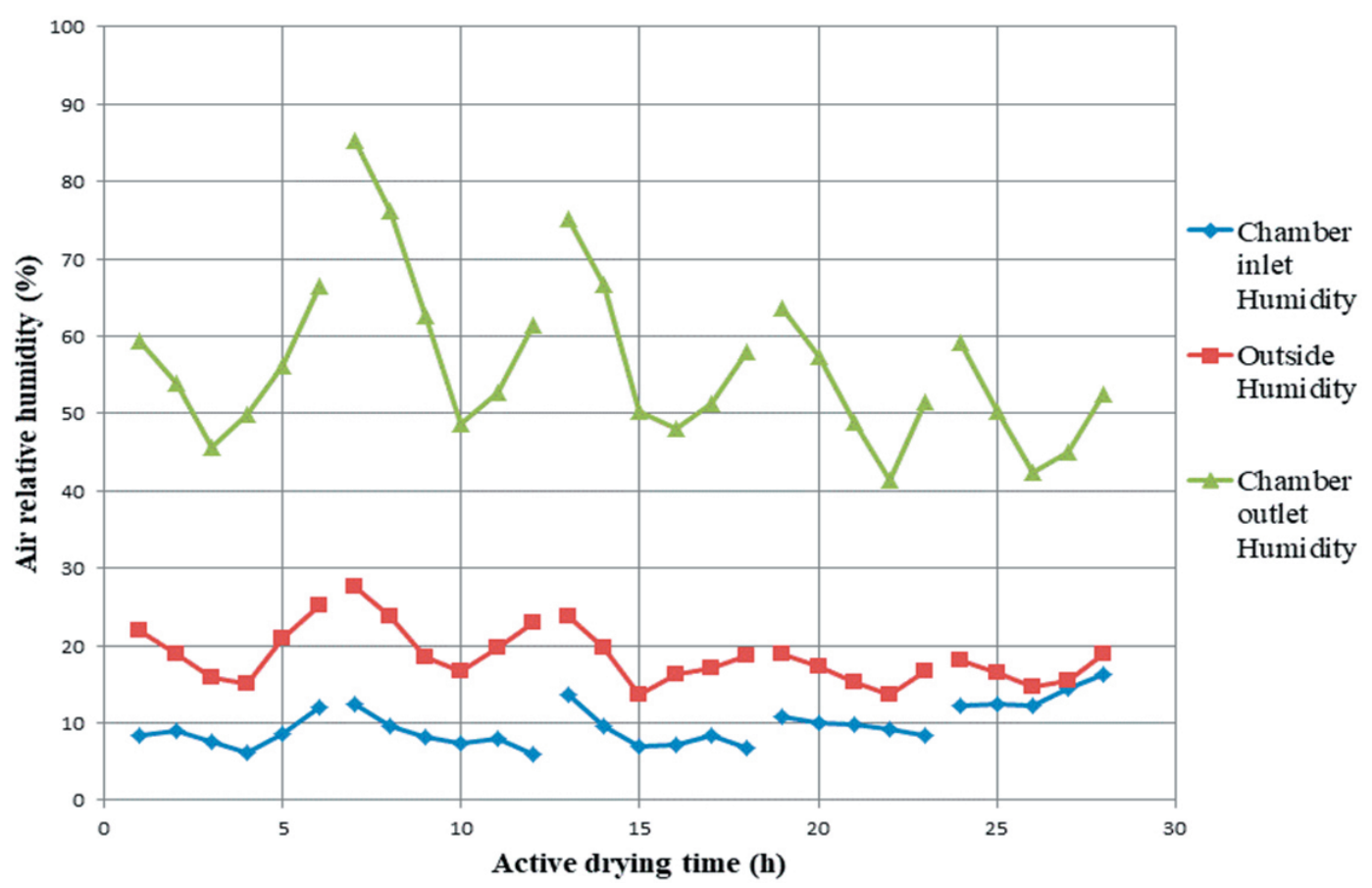

Fig. 6. Humidity change in three different locations in the device during the drying time.

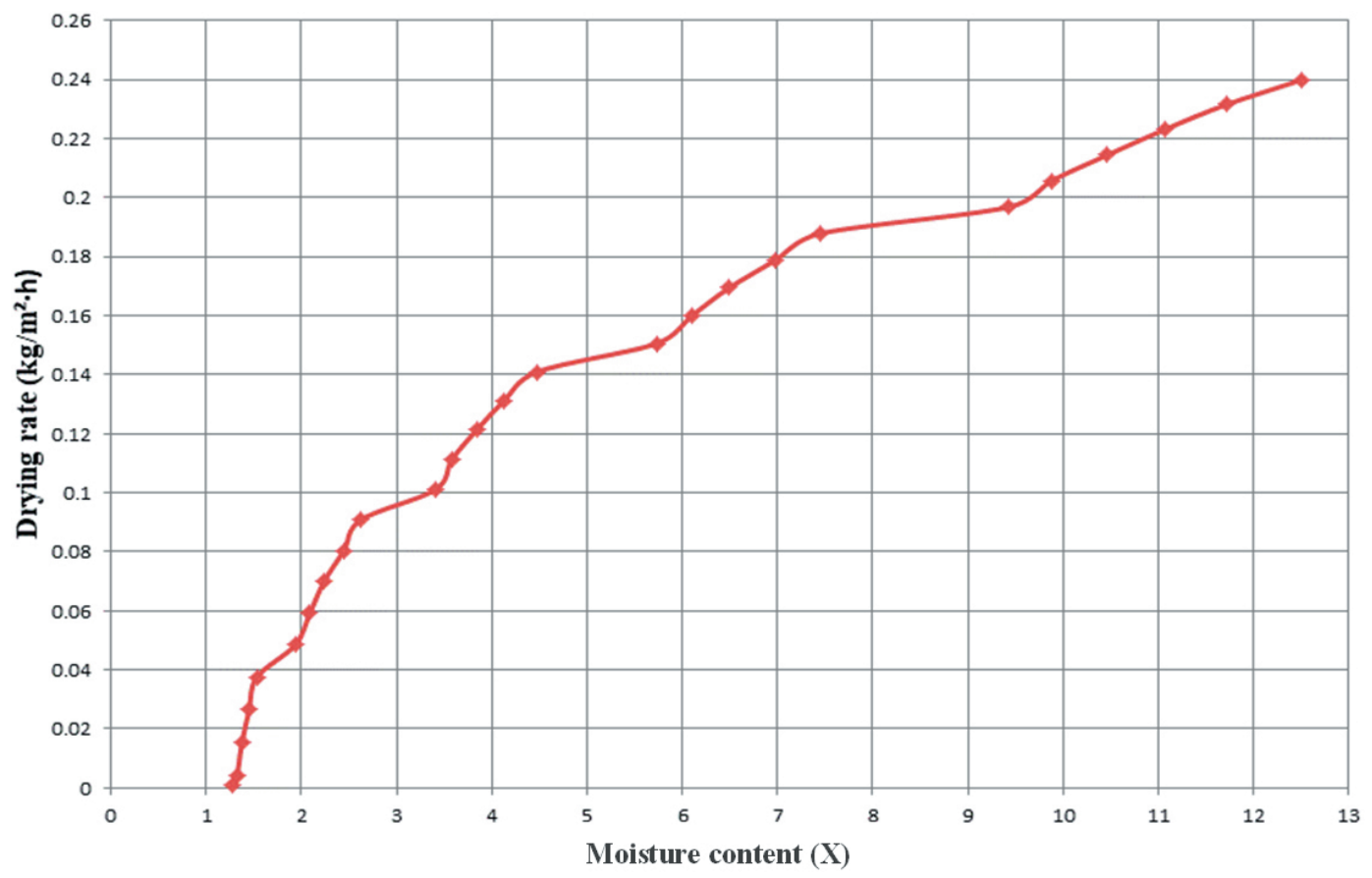

Fig. 7. Dependence of drying rate on moisture content. 
calculate the drying rate.

$$
D R=-\frac{m_{s}}{A_{a}} \frac{\mathrm{d} X}{\mathrm{~d} t}
$$

Where $m_{s}$ is mass of the bone-dry material in dried product $(\mathrm{kg}), A_{a}$ is fresh tomato slices surface area $\left(\mathrm{m}^{2}\right)$ and $(\mathrm{d} X / \mathrm{d} t)$ is a derivative of the moisture content (dry basis) relative to time. $(\mathrm{d} X / \mathrm{d} t)$ was obtained by derivation of a third degree polynomial function of the moisture content versus active drying time. The polynomial function was obtained using a trend line of the measured experimental data. Fig. 7 shows the variation of drying rate with the solid phase moisture content. When the moisture content of tomato slices decreases, the drying rate also decreases. Despite the high moisture content of tomato slices, the drying curve does not show any constant drying rate period. However, the drying rate decrease at the beginning of the process is much slower. Non-smooth behavior of the drying curve shown in Fig. 7 is due to the intermittent active drying mode.

The sample surface area, $A_{a}$, was considered to be constant during the drying in this study. However, the sample shrinkage can influence the shape of the drying curve. The effect of the sample shrinkage can dim the drying rate decrease at lower solid phase moisture content.

\section{Conclusions}

An energy independent indirect solar dryer was developed and tested by drying tomato slices. Measurement of air temperature and air relative humidity change after passing the collector and drying chamber showed that at the given geographical location, the dryer can effectively work also during winter season.

Under the climatic conditions in Kabul (Afghanistan) at the period of the experiment (end of December, winter, ambient day temperature: $10-17^{\circ} \mathrm{C}$, air relative humidity: $13-23 \%$, air pressure: $80-82 \mathrm{kPa}$ ), five days (five hours per day) were sufficient for $9 \mathrm{~mm}$ thickness sliced tomato drying in an energy independent indirect solar dryer. The average air temperature increase after passing through the collector was $30^{\circ} \mathrm{C}$. The air relative humidity decreased by around $7 \%$ after passing through the collector and increased by around $30 \%$ after passing through the drying chamber. During summer, when the sun radiation is more intensive, the drying time for sliced tomato with a $9 \mathrm{~mm}$ thickness of slices decreased from $25 \mathrm{~h}$ to $15 \mathrm{~h}$. Under these conditions, only two days of drying (7.5 h of sunshine each day) were necessary for sliced tomatoes drying compared to five days required in winter. The sample thickness showed the same effect as well. By increasing the sample thickness from $9 \mathrm{~mm}$ up to $12 \mathrm{~mm}$, the active drying time in summer season increased from $15 \mathrm{~h}$ up to $20 \mathrm{~h}$, which took three days of drying.

Approximately $90 \%$ of the product mass was lost during the drying process. Lower relative humidity and lower ambient pressure of upland geographical locations enable effective indirect solar drying also during the winter season.

\section{Acknowledgement}

This work was supported by the Grant APVV-15-0148 from the Agency for Supporting Research and Development of Slovakia and the project SAMRS/2016/AFG/01/01 of the Slovak Agency for International Development Cooperation.

\section{References}

Abida J, Rayees B, Masoodi FA (2014) International Food Research Journal 21: 839-848.

Abur BT, Dan-Dakouta H, Egbo G (2014) International Journal of Advanced Engineering and Research Studies 3: 166-171.

Acuña L, Morero RD, Bellomio A (2011) Food and Bioprocess Technology 4: 1029-1049.

Aiswarya MS, Divya CR (2015) International Research Journal of Engineering and Technology 2: 1948-1953.

Akpinar EK (2010) Energy Conversion and Management. 51: 2407-2418.

Amini MH, Hamdam SM (2017) International Journal of Pharmacognosy \& Chinese Medicine 1(3): 000118.

Barrett DM, Lloyd B (2012) Journal of the Science of Food and Agriculture 92: 7-22.

Bhardwaj ML (2012) In: Bhardwaj ML, Sharma HD, Kumar M, Kumar, R, Kansal S, Thakur K, Singh SP, Kumar D, Kumari S, Gupta M, Sharma V (Eds) Vegetable production under changing climate scenario (pp 13-18). Dr Y S Parmar University of Horticulture and Forestry, Nauni, Solan, Himachal Pradesh, India.

Boughali S, Benmoussa H, Bouchekima B, Mennouche D, Bouguettaia H, Bechki D (2009) Solar Energy 83: 2223-2232.

El Khadraoui A, Bouadila S, Kooli S, Farhat A, Guizani A (2017) Journal of Cleaner Production 148: 37-48.

Finck-Pastrana AG (2014) Energy Procedia 57: 29842993.

Jahangiri M, Haghani A, Mostafaeipour A, Khosravi A, Raeisi HA (2019) Renewable \& Sustainable Energy Reviews 99: 169-190.

Kadam PS, Jadhav BA, Salve RV, Machewad GM (2012) Journal of Food Processing and Technology 3: 135.

Karam MC, Petit J, Zimmer D, Djantou EB, Scher J (2016) Journal of Food Engineering 188: 32-49.

Kemal-ur-Rahim K (2003) FAO Horticulture Project (pp 7-45). FAO, Kabul.

Kudra T, Mujumdar AS (2009) Advanced Drying Technologies. CRC Press, Boca Raton.

Manaa S, Younsi M, Moummi N (2013) Energy Procedia 36: 511-514. 
Mathavi V, Sujatha G, Bhavani Ramya S, Karthika Devi B (2013) International Journal of Advances in Engineering \& Technology 5: 176-187.

Mehta P, Samaddar S, Patel P, Markam B, Maiti S (2018) Solar Energy 170: 671-681.

Ministry of Industry and Commerce, Islamic Republic of Afghanistan (2018) Afghanistan's National Export Strategy 2018-2022: Dried Fruits and Nuts Sector. International Trade Centre, Geneva.

Mohamed LA, Kane CSE, Kouhila M, Jamali A, Mahrouz M, Kechaou N (2008) Energy Conversion and Management 49: 940-946.

Mujumdar AS (Ed) (2014) Handbook of Industrial Drying ( $4^{\text {th }}$ ed). CRC Press, Boca Raton.

Mulet A, Cárcel JA, Sanjuán N, Bon J (2003) Food Science and Technology International 9: 215-221.

Phadke PC, Walke PV, Kriplan VM (2015) ARPN Journal of Engineering and Applied Sciences 10: 3360-3371.

Pu HJ, Li ZF, Hui J, Vijaya Raghavan GS (2016) Journal of Food Engineering 190: 167-175.

Rahman MS (Ed) (2007) Handbook of Food Preservation $\left(2^{\text {nd }}\right.$ ed). CRC Press, Boca Raton.

Rasoly M, Chandrashekar HM (2018) International Journal of Research in Business Studies and Management 5(5): 16-22.

Rathore NS, Panwar NL (2010) Applied Energy 87: 2764-2767.

Royen MJ, Noori AW, Haydary J (2018) Acta Chimica Slovaca, 11: 134-140.

Sagar VR, Kumar PS (2010) Journal of Food Science and Technology 47: 15-26.

Salman DA (2017) Protecting food, environmental, and water security in the Middle East and South Asia: Opportunities for Iraq and Afghanistan. New Mexico State University, Las Cruces.
Senadeera W, Alves-Filho O, Eikevik T (2013) Food and Bioproducts Processing 91: 549-557.

Sengar SH, Khandetod YP, Mohod AG (2009) African Journal of Environmental Science and Technology 3: 265-271.

Shamekhi-Amiri S, Gorji TB, Gorji-Bandpy M, Jahanshahi M (2018) Case Studies in Thermal Engineering 12: 677-686.

Sharma A, Chen CR, Lan NV (2009) Renewable and Sustainable Energy Reviews 13: 1185-1210.

Shukla AK, Sudhakar K, Baredar P (2017) ResourceEfficient Technologies 3: 342-346.

Sontakke MS, Salve SP (2015) International Refereed Journal of Engineering and Science 4(4): 29-35.

Sormoli ME, Langrish TAG (2016) LWT - Food Science and Technology 72: 1-8.

Srisittipokakun N, Kirdsiri K, Kaewkhao J (2012) Procedia Engineering 32: 839-846.

Sunil V, Sharma A, Sharma N (2012) Procedia Engineering 38: 3260-3269.

Tiris C, Tiris M, Dincer I (1996) Applied Thermal Engineering. 16: 183-187.

Wang W, Li M, Hassanien RHE, Wang YF, Yang LW (2018) Applied Thermal Engineering 134: 310-321.

Ward M, Jalal A (2011) GAIN Report AF-2011-10: 2011 Afghan Agricultural Economy Update. US Department of Agriculture, Washington D.C.

World Bank (2014) Islamic Republic of Afghanistan Agricultural Sector Review: Revitalizing Agriculture for Economic Growth., Job Creation and Food Security. Report No: AUS9779. World Bank, Washington D.C.

Zoukit A, El Ferouali H, Salhi I, Doubabi S, Abdenouri N (2019) Renewable Energy 133: 849-860. 